\title{
O TRABALHO DOCENTE NO CONTEXTO DO ESTÁGIO SUPERVISIONADO REMOTO: REFLEXÕES DE PROFESSORAS DE INGLÊS PARA CRIANÇAS EM FORMAÇÃO INICIAL ${ }^{1}$
}

\author{
Teaching work in the context of Remote Teaching Practicum: Reflections of \\ Pre-service teachers of English to young learners
}

\author{
Leticia Vidotti dos SANTOS ${ }^{2}$ \\ Programa de Pós-graduação em Estudos da Linguagem \\ Universidade Estadual de Londrina \\ leticia_vidotti@hotmail.com \\ https://orcid.org/0000-0003-3646-4045 \\ Juliana Reichert Assunção TONELLI \\ Programa de Pós-graduação em Estudos da Linguagem \\ Universidade Estadual de Londrina \\ jtonelli@uel.br \\ https://orcid.org/0000-0001-5102-5847
}

\begin{abstract}
RESUMO: Este artigo objetiva discutir as reflexões de professoras de língua inglesa para crianças (LIC) em formação inicial sobre o trabalho desenvolvido na disciplina de estágio supervisionado em contexto remoto. Para tanto, analisamos transcrições de sessões reflexivas nas quais as participantes produziram textos autoavaliativos em situação de pós-trabalho. A natureza desta pesquisa é qualitativa e de cunho interpretativista (BORTONI-RICARDO, 2008), tendo como instrumento de geração de dados uma ferramenta que denominamos de 'Roda da Satisfação'. O trabalho se ancora no quadro teórico-metodológico do Interacionismo Sociodiscursivo (BRONCKART, 2007), sobretudo em sua vertente de estudos sobre as relações entre linguagem e trabalho docente (BRONCKART; MACHADO, 2004; MACHADO, 2007), dialogando com o campo da Ergonomia da Atividade (AMIGUES, 2004) e da formação de professores de LIC (TONELLI; CRISTOVÃO, 2010;
\end{abstract}

\footnotetext{
${ }^{1}$ Fruto de uma pesquisa desenvolvida no âmbito do curso de mestrado em Estudos da Linguagem em andamento; este artigo apresenta um recorte de uma investigação mais ampla acerca da formação inicial de professores de língua inglesa para crianças. Pesquisa aprovada pelo Comitê de Ética em Pesquisa Envolvendo Seres Humanos da Universidade Estadual de Londrina (CEP UEL), número de aprovação: 34790920.9.0000.5231.

${ }^{2}$ Bolsista da Coordenação de Aperfeiçoamento de Pessoal de Nível Superior (CAPES).
}

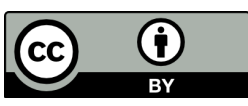


TONELLI, 2016; CIRINO; DENARDI, 2019). Os resultados apontam que as alunas-professoras valorizam amplamente o estágio supervisionado, visto que este espaço promove a união de conhecimentos teóricos e práticos relacionados ao ensino de LIC, viabilizando o desenvolvimento pessoal e profissional de professores em formação inicial. Esse aperfeiçoamento se constitui no coletivo de trabalho formado neste contexto, o qual é posto como fonte confiável de prescrições sobre o agir docente e como proporcionador da formulação de autoprescrições. PALAVRAS-CHAVE: Formação inicial de professores; Ensino de inglês para crianças; Reflexões sobre o trabalho docente; Estágio supervisionado remoto.

ABSTRACT: This article aims to discuss the reflections of pre-service teachers of English Language to young learners (ELYL) about the work developed during the teaching practicum in a remote context. For this, we analyzed transcripts of reflexive sessions in which participants produced self-evaluative texts in a post-work situation. This is a qualitative research of interpretative nature (BORTONI-RICARDO, 2008); as an instrument for data generation, we used a tool we have called 'Wheel of Satisfaction'. The research is based on the theoretical-methodological framework of Socio-discursive Interactionism (BRONCKART, 2007), especially on its studies about the relation between language and teaching work (BRONCKART; MACHADO, 2004; MACHADO, 2007), engaging in dialogue with the Ergonomic Approach to the Activity (AMIGUES, 2004) and the ELYL teachers' education. (TONELLI; CRISTOVÃO, 2010; TONELLI, 2016; CIRINO; DENARDI, 2019). The results point out that the student-teachers widely appreciate the teaching practicum, since this space promotes the linking of theoretical and practical knowledge related to the teaching of ELYL, enabling the personal and professional development of teachers in initial education. This improvement is constituted in the work collective established in this context, which is seen as a reliable source of prescriptions for teaching acting and as a means of formulating self-prescriptions. KEYWORDS: Teachers' initial education; Teaching English to young learners; Reflections on teaching work; Remote teaching practicum.

\section{INTRODUÇÃO}

$\mathrm{Na}$ atual conjuntura educacional, notamos a crescente oferta do ensino de língua inglesa para crianças (de agora em diante LIC) nos mais diversos contextos escolares públicos ou privados. Como consequência, também observamos um significativo aumento de pesquisas ocupadas em investigar as inúmeras questões que perpassam a 
formação dos professores que deverão atuar nestes cenários emergentes. Nessa direção, apoiando-nos num ponto de vista que considera a prática docente enquanto trabalho (MACHADO, 2009), compreendemos que essa atividade "vai além dos limites da sala de aula e da relação aluno-professor" (PÉREZ, 2011, p. 233), merecendo, assim, ser cuidadosamente analisada.

Desse modo, o objetivo central deste artigo reside em identificar como duas professoras de LIC em formação inicial tematizam, em sessões reflexivas pós-tarefa, o trabalho docente desenvolvido ao longo das práticas do estágio curricular supervisionado, ocorridas em meio remoto em razão da pandemia ocasionada pela covid-19. Para tanto, baseamo-nos no quadro teórico-metodológico do Interacionismo Sociodiscursivo (doravante ISD) (BRONCKART, 2007) que investiga as relações entre linguagem e trabalho docente (BRONCKART; MACHADO, 2004; MACHADO, 2007), promovendo um diálogo entre o campo da Ergonomia da Atividade (AMIGUES, 2004) e da formação de professores de LIC (TONELLI; CRISTOVÃO, 2010; TONELLI, 2016; CIRINO; DENARDI, 2019), dentre outros estudos referenciados.

Além desta introdução, este texto está organizado em seis partes. Na primeira, apresentamos algumas noções acerca do trabalho docente na perspectiva do aporte teórico-metodológico adotado, a fim de discutir os elementos que constituem a atividade do professor. Em seguida, discorremos sobre os motivos que nos levam a analisar os textos produzidos por docentes de LIC, tecendo considerações entre linguagem e trabalho docente. $\mathrm{Na}$ seção posterior, discutimos a formação inicial de professores de LIC, evidenciando a importância do estágio enquanto espaço formativo. Adiante, temos a apresentação dos caminhos metodológicos percorridos durante a constituição da pesquisa e o desenvolvimento das análises acerca dos discursos das participantes. Por fim, encerramos o artigo tecendo algumas considerações finais.

\section{O TRABALHO DOCENTE NA PERSPECTIVA DO INTERACIONISMO SO- CIODISCURSIVO}

A partir de uma abordagem ancorada nas noções de psicologia da linguagem de Vygotsky e de outras correntes das ciências humanas, o ISD se configura enquanto um construto teórico-metodológico que se ocupa em "analisar as condutas humanas como ações significantes” (BRONCKART, 2007, p. 13). De acordo com Bronckart (2007), as ações de linguagem são empiricamente materializadas em textos e/ou discursos produzidos diante das necessidades e interesses dos agentes e das condições que circundam a produção dos sujeitos. Nesse sentido, para o ISD, esses textos se associam 
a uma entidade genérica, com "formas relativamente estáveis e típicas de construção do todo" (BAKHTIN, 2003, p. 282), denominada por Bronckart (2007) de gêneros de textos/textuais.

Nesse cenário, o ISD parte do pressuposto de que as práticas linguageiras ocupam papel central no desenvolvimento humano, visto que a "linguagem é tida como uma atividade significante que nos constitui ao mesmo tempo em que a constituímos" (CRISTOVÃO, 2011, p. 7). Em vista disso, convém ressaltar que as ações dos sujeitos só podem ser compreendidas "por meio de interpretações, produzidas principalmente com a utilização da linguagem, em textos dos próprios actantes ${ }^{3}$ ou observadores dessas ações" (MACHADO et al., 2004, p. 90). Assim, o quadro teórico-metodológico do ISD tem como um de seus objetos de estudo as ações de linguagem empreendidas no âmbito das interações humanas situadas sócio-historicamente.

Nessa perspectiva, a partir dos pressupostos sociointeracionistas de investigação do agir humano, temos um desdobramento do ISD no campo de estudos acerca das relações entre a linguagem e o trabalho docente. De acordo com Machado (2009), a atividade docente é um sistema triádico composto por: 1) professor (agente da transformação), 2) aluno (agente a ser transformado) e 3) ferramentas de transformação/ mediação. De forma resumida, podemos dizer que o trabalho docente é composto pelas ações que o professor empreende em diversas situações com o intuito de oportunizar aos alunos meios de aprendizagem acerca da disciplina trabalhada e o desenvolvimento de capacidades específicas. Para isso, esse profissional se vale de instrumentos que mediam essa interação e se pauta em prescrições que regulam suas ações no contexto de ensino (MACHADO, 2007).

Além das características supracitadas, Amigues (2004) aponta que, embora o objeto central da atividade ${ }^{4}$ do professor consista em organizar meios para que os alunos se apropriem de um objeto do conhecimento, o trabalho docente também se dirige "à instituição que o emprega, aos pais, a outros profissionais" (AMIGUES, 2004, p. 41). Dessa forma, o autor mencionado defende que a atividade docente é socialmente situada, sendo construída por meio das relações coletivas entre os diversos sujeitos que fazem

\footnotetext{
3 'O termo actante, mais neutro do que 'agente' ou 'ator', é utilizado para nos referirmos a qualquer entidade que é colocada no texto como sendo a fonte de um agir [...]" (MACHADO et al., 2004, p. 92).

${ }^{4}$ Conforme aponta Amigues (2004), é necessário distinguir os conceitos tarefa e atividade. Segundo o autor, tarefa se refere "ao que deve ser feito", enquanto a atividade "corresponde ao que o sujeito faz mentalmente para realizar essa tarefa" (AMIGUES, 2004, p. 39, grifos do autor). Revista X, v. 16, n. 6, p. 1632-1657, 2021. 
parte desse sistema e mediada por ferramentas. É nessa perspectiva que apresentamos uma síntese da proposta de Amigues (2004) exposta na Figura 1:

Figura 1: Objetos constitutivos da atividade docente.

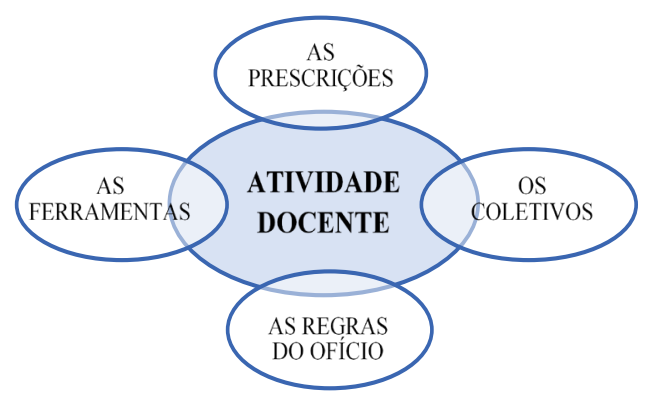

Fonte: as autoras, com base em Amigues (2004).

Conforme é possível observar na Figura 1, o trabalho do professor é perpassado e constituído por quatro objetos (AMIGUES, 2004). As prescrições fornecem orientações que regulamentam e amparam as ações docentes e, ao mesmo tempo, constituem a atividade do professor. Conforme aponta Souza-e-Silva (2004, p. 90), as prescrições são "às vezes muito coercitivas, outras extremamente vagas, por vezes contraditórias", mas ainda assim não podem ser ignoradas pelo professor, visto que são elas que orientam "o que é possível fazer, o que é autorizado, tolerado ou proibido”. Quanto à sistematização das prescrições, essas se materializam em textos prescritivos (provindos de instituições externas ao agente) e em textos autoprescritivos (produzidos pelo próprio trabalhador em situações de trabalho) (MACHADO et al., 2004).

Nesse ponto, consideramos relevante destacar algumas consequências da inexistência de políticas públicas e de diretrizes (AVILA; TONELLI, 2018) que tragam orientações específicas para o ensino de LIC e que prevejam a formação necessária do profissional que deverá atuar nesse campo. Uma vez que o ensino de LIC se configura enquanto opcional, o trabalho do professor nesses contextos não conta com prescrições sistematizadas em documentos oficiais ou em leis educacionais. Assim, esses profissionais se pautam apenas nas prescrições advindas de agentes externos que supervisionam seu ambiente de atuação (como as orientações de coordenadores pedagógicos) e em suas autoprescrições para a atividade docente.

Diante desse cenário carente de prescrições que direcionam e amparam o trabalho do professor de LIC, defendemos, portanto, a importância da inserção desse 
profissional em contextos de formação inicial e continuada, buscando amparar a atuação desse professor. Por isso, compreendemos que seja necessário criar espaços no âmbito dos cursos de licenciatura em língua inglesa para que essa formação teórica e prática do docente de LIC possa ocorrer, conforme apontam Cirino e Denardi (2019), por exemplo. Um desses espaços de formação é o estágio supervisionado, o qual é posto como contexto do agir docente relatado neste artigo. Assim, entendemos que esse preparo para a atividade docente possa servir como um meio de sistematizar o ensino de LIC como trabalho.

Adiante, temos os coletivos de trabalho como outro objeto constitutivo da atividade docente. Segundo Amigues (2004), e em contrapartida à visão individualista acerca do trabalho docente, a atividade do professor se constitui na (e por meio da) coletividade. Para além de ser uma resposta a uma prescrição administrativa de trabalho em equipe, a atividade coletiva entre professores busca mobilizar esses profissionais de modo a "dar uma resposta comum às prescrições" (SOUZA-E-SILVA, 2004, p. 90). Assim, por mais que haja uma singularidade/individualidade nas ações dos professores, há sempre um reflexo de ordem coletiva nessa atividade, uma vez que o trabalho docente também se constitui por meio e no meio da coletividade.

Já as regras do ofício, construídas também por meio dos coletivos, são consideradas como um elemento que une os profissionais entre si, colocando-se como "uma memória comum e uma caixa de ferramentas, cujo uso especificado pode, com o tempo, gerar uma renovação nos modos de fazer e pode ainda ser fonte de controvérsias profissionais" (AMIGUES, 2004, p. 43, grifos do autor). Ademais, cabe destacar que as regras do ofício se compõem por gestos genéricos, relacionados ao conjunto de professores, e por gestos específicos, referentes à disciplina de atuação docente.

Por fim, as ferramentas também constituem o trabalho docente enquanto meios utilizados pelos professores em situação de trabalho para mediar o processo de ensinoaprendizagem. Como Amigues (2004) assinala, o professor se utiliza de ferramentas pré-existentes e/ou as modificam para que possa atingir seus objetivos, de acordo com as necessidades emergidas em seu contexto de atuação. Desse modo, ao passo que o docente se apropria dessas ferramentas (e ao mesmo tempo é modificado por elas), o professor passa a transformá-las em instrumentos para a ação (AMIGUES, 2004; MACHADO, 2007).

Em face às considerações tecidas, destacamos a complexidade de dimensões que perpassam a atividade docente, permitindo-nos atestar que o trabalho do professor não se limita à tarefa de 'dar aulas'. Nesse sentido, afirmamos que, para além dos objetos previamente explorados, o trabalho do professor se circunscreve, ainda, "em 
uma rede múltipla de relações sociais existentes em um determinado contexto sóciohistórico e inserido em um sistema de ensino em um sistema educacional específico" (MACHADO, 2007, p. 92).

Assim, ratificamos que o contexto é um elemento que exerce extensiva influência sobre o agir dos indivíduos. Daí a necessidade de investigarmos e analisarmos textos específicos produzidos pelos sujeitos em investigação, a fim de que possamos compreender qual é o pano de fundo que circunda a produção desses indivíduos e quais as influências desse contexto nas produções dos sujeitos. É nesta perspectiva, portanto, que discorremos, na seção posterior, sobre a relevância da análise de textos produzidos pelos professores.

\section{POR QUE ANALISAR TEXTOS PRODUZIDOS POR PROFESSORES DE LÍNGUA INGLESA PARA CRIANÇAS?}

Pautando-nos em uma abordagem sociointeracionista que considera a linguagem enquanto um dos principais instrumentos de desenvolvimento humano, entendemos que é também por meio das práticas linguageiras que os sujeitos constroem e exteriorizam suas representações individuais na e sobre a atividade docente, permitindo-nos uma "compreensão maior das relações linguagem/trabalho" (BRONCKART; MACHADO, 2004, p. 135). Nesse sentido, respaldadas no quadro teórico-metodológico do ISD e sob a mesma ótica dos autores supracitados, Francescon e Cristovão (2020) defendem a importância da criação de espaços que promovam reflexividade sobre o trabalho do professor em momentos de formação inicial, assim como propomos na presente pesquisa.

Conforme assinalado por Francescon e Cristovão (2020), a reflexividade acerca da atividade docente fomenta o desenvolvimento profissional dos professores em processo de formação, uma vez que os fazem "refletir, repensar, interpretar e reinventar suas próprias ações" (FRANCESCON; CRISTOVÃO, 2020, p. 377). Desse modo, compreendemos que as representações dos agentes, materializadas em suas práticas linguageiras, bem como as atividades de reflexão sobre a prática docente, são meios essenciais que nos permitem compreender o trabalho do professor exteriorizado em suas reflexões.

Logo, para interpretarmos textos produzidos por professores em formação, fazse necessária a adoção de critérios bem definidos e fundamentados, que nos permitam interpretar de maneira crítica o discurso em análise. Sob esse viés, realizamos a leitura dos dizeres das participantes por meio da utilização de alguns dos conceitos do modelo de análise de textos proposto por Bronckart (2007). Desse modo, neste artigo, damos enfoque à análise dos tipos de discursos mobilizados pelas professoras, cuja proposta é 
identificar se e de que maneira elas se valem da implicação discursiva como um recurso linguístico que nos permita caracterizar o reconhecimento das participantes acerca da coletividade do trabalho docente.

É nessa perspectiva, portanto, que justificamos a necessidade do desenvolvimento de pesquisas que se ocupem em analisar o agir docente representado nos textos dos trabalhadores/professores de LIC em processos reflexivos sobre a prática docente. Isso porque compreendemos que

conhecer o métier do professor de LIC durante a formação inicial, por meio de estudo dos gestos profissionais, das adaptações que fazem na rotina de sala de aula, demandando decisões, ações, fala, movimentos variados proporciona ao professor em formação inicial a oportunidade de compreender o ensino - de LIC - como trabalho (TONELLI; BROSSI; FURIO, 2018, p. 238).

Sendo assim, consideramos relevante destacar que a análise do agir docente pode ser realizada a partir de textos diversos, sendo eles divididos em: 1) textos anteriores ao agir em situação de trabalho; 2) textos posteriores à realização deste trabalho e 3) textos produzidos em situação de trabalho (LOUSADA; ABREU-TARDELLI; MAZILLO, 2007, p. 241). A fim de promover uma melhor explicação sobre essas tipologias de textos, apresentamos o Quadro 1: 
Quadro 1: Tipos de textos a serem analisados.

\begin{tabular}{|c|c|c|}
\hline $\begin{array}{l}\text { Tipos de } \\
\text { textos }\end{array}$ & Definição & Exemplos \\
\hline $\begin{array}{c}\text { Textos } \\
\text { anteriores } \\
\text { ao agir em } \\
\text { situação de } \\
\text { trabalho }\end{array}$ & $\begin{array}{l}\text { Podem ser de ordem institucional } \\
\text { ou produzidos pelos próprios } \\
\text { actantes antes de agir. Subdividem- } \\
\text { se em: 1) textos prescritivos, } \\
\text { que regulamentam e definem as } \\
\text { condições de realização das tarefas } \\
\text { previstas, e 2) textos da nascente } \\
\text { do agir, que perpassam a fonte do } \\
\text { agir docente, mas não apresentam } \\
\text { prescrições explícitas quanto às } \\
\text { ações do professor. }\end{array}$ & $\begin{array}{l}\text { 1) Textos prescritivos: planos de } \\
\text { aula, texto de apresentação de curso, } \\
\text { material didático, programa de curso } \\
\text { etc. } \\
\text { 2) Textos da nascente do agir: Lei } \\
\text { de Diretrizes e Bases da Educação } \\
\text { Nacional (LDB), Parâmetros } \\
\text { Curriculares Nacionais (PCN), } \\
\text { decretos, entre outros documentos e } \\
\text { leis sobre o ensino. }\end{array}$ \\
\hline $\begin{array}{l}\text { Textos } \\
\text { posteriores à } \\
\text { realização do } \\
\text { trabalho }\end{array}$ & $\begin{array}{l}\text { São textos avaliativos/reflexivos } \\
\text { em que os próprios actantes ou } \\
\text { observadores/pesquisadores } \\
\text { externos expõem suas } \\
\text { representações sobre o trabalho } \\
\text { realizado previamente. }\end{array}$ & $\begin{array}{l}\text { Textos de entrevistas posteriores ao } \\
\text { trabalho com o professor; textos de } \\
\text { diários reflexivos produzidos após as } \\
\text { aulas; textos advindos de situações } \\
\text { de autoconfrontações simples e } \\
\text { cruzadas; relatórios de estágio, entre } \\
\text { outros. }\end{array}$ \\
\hline $\begin{array}{c}\text { Textos } \\
\text { produzidos em } \\
\text { situação de } \\
\text { trabalho }\end{array}$ & $\begin{array}{l}\text { Os textos produzidos em situação } \\
\text { de trabalho são realizados durante a } \\
\text { ação do professor em seu contexto } \\
\text { de ensino. }\end{array}$ & $\begin{array}{l}\text { Textos provenientes das gravações } \\
\text { de aulas; textos resultantes dos } \\
\text { momentos de interação entre } \\
\text { professor e aluno durante as aulas, } \\
\text { entre outros textos produzidos nesse } \\
\text { contexto. }\end{array}$ \\
\hline
\end{tabular}

Fonte: as autoras, com base em Lousada, Abreu-Tardelli e Mazillo (2007).

Em face ao Quadro 1, ressaltamos que, com o objetivo de identificarmos e interpretarmos o agir educacional das professoras participantes, o foco das nossas análises recai sob os textos autoavaliativos produzidos por elas após a realização do trabalho no âmbito do estágio supervisionado. A partir do referencial teórico adotado nesta pesquisa, concluímos que tais textos estão intimamente ligados aos textos anteriores Revista X, v. 16, n. 6, p. 1632-1657, 2021. 
ao trabalho, visto que os momentos reflexivos pós-trabalho também revelam as reflexões das professoras acerca dos momentos de planejamento do ensino remoto de LIC por meio de gêneros textuais.

Destacamos, ainda, que os textos analisados se materializam em sessões reflexivas que foram realizadas entre a primeira autora do artigo e as participantes por meio de interações virtuais que ocorreram individualmente com cada participante. Ademais, consideramos que esses diálogos promoveram espaços para que as professoras em formação inicial construíssem "representações sobre suas intenções, seus motivos e suas capacidades" (MACHADO et al., 2004, p. 91) e refletissem sobre a relevância das práticas realizadas para o seu desenvolvimento enquanto professoras de LIC.

Diante das reflexões tecidas até este momento acerca de importantes conceitos sobre a atividade docente, damos continuidade ao presente trabalho com a seção seguinte, na qual discutimos e problematizamos a formação inicial do professor de LIC no âmbito dos cursos de letras em contexto nacional.

\section{FORMAÇÃO INICIAL DE PROFESSORES E PROFESSORAS DE LÍNGUA INGLESA PARA CRIANÇAS: O ESTÁGIO SUPERVISIONADO COMO ES- PAÇO DE DESENVOLVIMENTO}

A formação inicial e continuada de professores e professoras para atuar no ensino de LIC vem sendo amplamente discutida dado o crescimento exponencial da oferta de línguas nos anos iniciais do ensino fundamental e na educação infantil tanto em contexto privado quanto público (TONELLI; AVILA, 2020).

Em concordância com Brito e Ribas (2018), compreendemos que o estágio supervisionado não deve ser concebido dicotomicamente, como um momento em que teorias são aplicadas à prática, mas, sim, como "um espaço de formação e de possíveis deslocamentos discursivos, por promover a revisitação de teorias estudadas pelo licenciando e a ressignificação dos processos de ensino-aprendizagem de uma outra língua (BRITO; RIBAS, 2018, p. 245).

No que diz respeito à formação inicial para o contexto em tela, esta, quando é ofertada pelos cursos de letras, tem sido realizada, em sua grande maioria, no âmbito do estágio supervisionado, conforme nos conta Tonelli (2016). Importa enfatizar que embora não haja consenso sobre o perfil do docente a atuar neste espaço, há mais de uma década, Tonelli e Cristovão (2010) já chamavam a atenção para o papel dos cursos de letras na formação de professores de LIC. 
Mais recentemente, Cirino e Denardi (2019) problematizam esta questão e discutem como os cursos de formação têm organizado seus currículos para atender a esta demanda. No que concerne ao estágio supervisionado, as autoras colocam que

O momento dos estágios é aquele em que o acadêmico tem contato com uma sala de aula real e tem a possibilidade de conhecer pelo menos o mínimo do funcionamento de uma aula. Talvez esse contato tão breve não seja o suficiente para sanar todas as dúvidas dos futuros professores, mas eles já podem ter uma ideia de como são seus futuros alunos. Caso esses acadêmicos tivessem a oportunidade de ter preparação e fazer estágio com o público infantil também, muitos poderiam se afeiçoar com esses alunos ou ao contrário, perceber que não têm o perfil para trabalhar com crianças (CIRINO; DENARDI, 2019, p. 220).

Portanto, é neste cenário arbitrário de carência de prescrições, agregado à grande demanda da atuação profissional em contextos de ensino de LIC, que observamos a iniciativa de formação de professores de LIC por parte de alguns cursos de letras em âmbito nacional (TONELLI; BROSSI; FURIO, 2018). Assim, compreendemos que a oferta da disciplina de estágio supervisionado em LIC se apresenta como uma iniciativa institucional empreendida na tentativa de suprir as necessidades formativas relacionadas ao campo de atuação docente.

\section{CAMINHOS METODOLÓGICOS: CONTEXTO DA PESQUISA, PARTICI- PANTES E GERAÇÃO DOS DADOS}

A natureza desta pesquisa é de base qualitativa e de cunho interpretativista (BORTONI-RICARDO, 2008), uma vez que se propõe a observar e interpretar os textos produzidos pelas participantes que integram esta investigação levando em consideração o contexto onde elas se encontram inseridas. Quanto à tipologia, esta pesquisa apresenta cunho colaborativo-intervencionista, visto que foi perpassada por um trabalho de colaboração entre professoras pesquisadoras e professoras em formação inicial, além de contar com a intervenção do primeiro grupo em todo o processo de planejamento das aulas e, posteriormente, nos momentos de reflexão sobre as práticas supervisionadas.

Além disso, ressaltamos que este trabalho parte de um cenário mais amplo que envolveu o acompanhamento de graduandas do curso de letras-inglês de uma universidade pública do norte do Paraná ao longo do segundo semestre letivo de 2020. Desse modo, temos como contexto de pesquisa a prática supervisionada de estágio realizada em um curso de LIC oferecido pelo Laboratório de Línguas do Departamento de Letras 
Estrangeiras Modernas (LEM) da referida universidade. Destacamos, ainda, que foi nesse mesmo contexto que a primeira autora deste artigo, sob supervisão da segunda autora, também realizou seu estágio de docência na graduação, atuando como professora estagiária na disciplina de estágio supervisionado em LIC.

Além das autoras deste trabalho, as duas participantes ${ }^{5}$ que integram esta investigação são alunas do terceiro e quarto ano do curso de letras-inglês da universidade mencionada. Convém mencionar que, em razão de nossos compromissos éticos, preservarmos a identidade das duas professoras em formação inicial, assegurando, assim, a privacidade das participantes. Dessa maneira, identificamos as alunas-professoras nesta pesquisa por meio dos nomes fictícios de Ana para a graduanda do quarto ano e de Carolina para a graduanda do terceiro ano.

Os dados analisados neste artigo foram gerados ao final de um processo de elaboração colaborativa e de implementação de uma sequência didática $(\mathrm{SD})^{6}$ sobre o gênero História em Quadrinhos (HQ), em contexto totalmente virtual, em razão dos desafios impostos pela pandemia mundial de covid-19. Para isso, reunimo-nos individualmente com as participantes por meio da plataforma virtual Google Meet e realizamos sessões reflexivas acerca das atividades desenvolvidas ao longo do estágio curricular supervisionado no contexto de ensino de LIC. Tal processo reflexivo se deu por meio da aplicação de uma ferramenta que denominamos de 'Roda da Satisfação'.

A 'Roda da Satisfação' é uma adaptação de um instrumento do campo da psicologia denominado de 'Roda da Vida'. Essa ferramenta "consiste num círculo em forma de gráfico de pizza em que o sujeito deverá avaliar, numa escala de 1 a 10, alguns aspectos de sua vida" (TORRESAN; PESSOTTO; BUENO, 2018, p. 134). Sob esse viés, a partir do nosso objetivo de compreender como as participantes avaliavam o caminho percorrido ao longo do estágio supervisionado, realizamos algumas modificações neste instrumento e selecionamos dez aspectos a serem abordados. Na Figura 2 apresentamos o modelo e a legenda da 'Roda da Satisfação':

\footnotetext{
${ }^{5}$ Em conformidade com os procedimentos éticos recomendados pelo Comitê de Ética em Pesquisa, as participantes leram, preencheram e assinaram um Termo de Consentimento Livre e Esclarecido (TCLE) consentindo com a gravação, transcrição, utilização e veiculação dos dados resultantes desta pesquisa. Tendo em vista o distanciamento social ocasionado pela pandemia de covid-19 e a adoção emergencial do ensino remoto durante o ano de 2020, o referido TCLE foi enviado aos participantes via e-mail.

${ }^{6}$ De acordo com Dolz, Noverraz e Schneuwly (2011, p. 83), “uma 'sequência didática' é um conjunto de atividades escolares organizadas, de maneira sistemática, em torno de um gênero textual oral ou escrito".
} 
Figura 2: Modelo e legenda da 'Roda da Satisfação'.

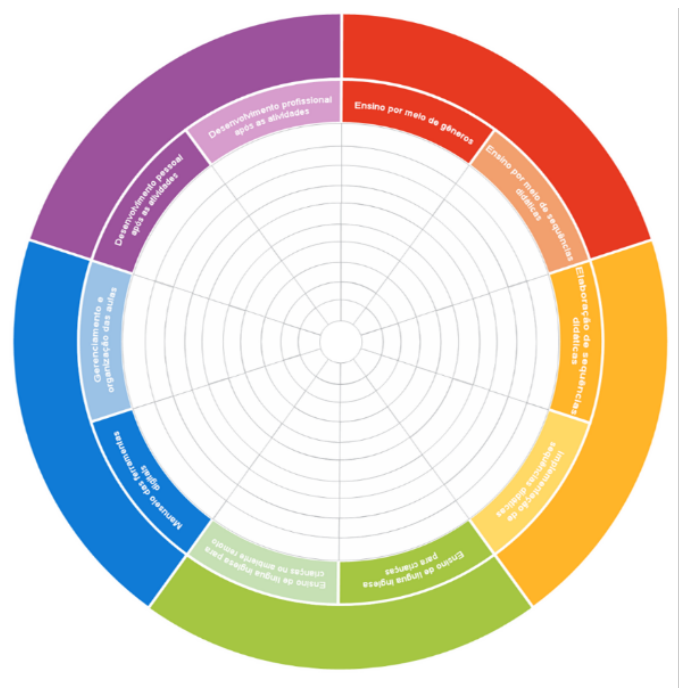

\begin{tabular}{|l|l|}
\hline COR & \multicolumn{1}{|c|}{ TEGÉPICO } \\
\hline & Ensino por meio de gêneros \\
\hline & Ensino por meio de sequências didáticas \\
\hline & Elaboração de sequências didáticas \\
\hline Implementação de sequências didáticas \\
\hline & Ensino de língua inglesa para crianças \\
\hline Ensino de língua inglesa para crianças no ambiente remoto \\
\hline Manuseio das ferramentas digitais \\
\hline & Gerenciamento e organização das aulas \\
\hline & Desenvolvimento pessoal após as atividades \\
\hline & Desenvolvimento profissional após as atividades \\
\hline
\end{tabular}

Fonte: as autoras.

Destacamos que dada a delimitação de nosso objetivo de pesquisa - discutir as representações de professoras em formação inicial sobre o trabalho do professor de LIC no contexto do estágio supervisionado - selecionamos apenas alguns desses tópicos como objeto de nossa análise. Quais sejam: 2) ensino por meio de sequências didáticas; 5) ensino de língua inglesa para crianças; 6) ensino de língua inglesa para crianças no ambiente remoto; 9) desenvolvimento pessoal após as atividades e; 10) desenvolvimento profissional após as atividades, conforme apresentamos na seção seguinte. Além disso, convém informar que os dados analisados consistem em transcrições das gravações obtidas nos momentos em que as participantes preenchiam a 'Roda da Satisfação' e tematizavam suas representações. Na seção a seguir trazemos as análises dos dados aqui descritos.

\section{ANALISANDO AS PERCEPÇÕES DAS PROFESSORAS DE LÍNGUA INGLESA PARA CRIANÇAS EM FORMAÇÃO INICIAL}

Com vistas a sistematizar a análise das transcrições e facilitar a compreensão por parte dos leitores, organizamos a discussão dos dados de acordo com alguns dos tópicos abordados na 'Roda da Satisfação'. 


\section{Ensino por meio de sequências didáticas}

Um dos primeiros tópicos discutido com as participantes foi o Ensino por meio de sequências didáticas, uma vez que pretendíamos entender quais eram as representações das professoras em formação inicial sobre esse dispositivo didático após terem elaborado e implementado uma SD para o ensino de LIC. Nesse ponto, ressaltamos que a elaboração de SD não foi um assunto completamente inusitado para as graduandas, uma vez que as duas já haviam cursado uma disciplina sobre o ensino de gêneros textuais durante a graduação em letras e até mesmo produzido uma SD voltada para o ensino de inglês para as séries finais do ensino fundamental II.

No entanto, de acordo com os relatos das participantes, ambas ainda não haviam tido a oportunidade de aplicar as SDs elaboradas, tendo se mantido apenas no campo teórico de construção desse material didático. Outro aspecto desafiador para as graduandas se relacionou ao público-alvo da SD a ser elaborada: crianças de oito a dez anos de idade. Isso posto, diante dos cenários descritos, gostaríamos de compreender qual era o nível de satisfação das professoras em formação inicial com o tópico mencionado. Observemos, inicialmente, a fala de Carolina disposta no Excerto 1:

\section{Excerto 1}

Carolina: Eu acho que o ensino por meio da sequência didática seria um dez. Porque assim, a gente vai trabalhando nisso, então, a gente já sabe muito bem do que a gente quer, o que a gente quer falar, qual é o nosso objetivo (grifo nosso).

O discurso de Carolina nos indica que ela se sente confortável com a proposta de ensino de LIC pautada no dispositivo SD. Segundo a aluna-professora aponta, ao adotar o dispositivo SD, é possível "saber o que a gente quer, o que a gente quer falar, qual é o nosso objetivo". Nesse sentido, compreendemos que ela acredita que essa ferramenta (AMIGUES, 2004) pode auxiliar na sistematização dos objetivos de ensino-aprendizagem e dos 'conteúdos' a serem ensinados, o que nos leva a inferir que a professora em formação inicial poderá se utilizar da elaboração de novas SDs em suas futuras práticas de ensino de LIC em outros contextos de atuação. 
Além disso, ao utilizar o pronome pessoal de primeira pessoa 'a gente' ${ }^{7}$, Carolina mobiliza o tipo de discurso interativo ${ }^{8}$ (BRONCKART, 2007) de cunho implicado. Por meio dessa marca linguística no discurso da participante, verificamos que ela reconhece o trabalho coletivo de um 'nós' que ultrapassa uma autoria individual, presentificando a dimensão coletiva do trabalho, conforme Amigues (2004). Como o autor pontua, "esses coletivos assumem formas diversas" (AMIGUES, 2004, p. 43). No caso do contexto explorado neste artigo, especificamente, notamos o surgimento de um coletivo de professores de LIC em formação inicial. Esses mesmos sujeitos também integram outros coletivos, como o coletivo de professores da disciplina de língua inglesa, o coletivo de professores estagiários, o coletivo de professores em processo formativo, dentre outros que também perpassam e constituem esses indivíduos.

Em sentido oposto do discurso de Carolina, a participante Ana demonstra ter um ponto de vista um pouco diferente acerca da mesma questão levantada, como vemos no Excerto 2:

\section{Excerto 2}

Ana: É...eu acho que 7, porque eu acho que se eu for ensinar por conta, sem ajuda, eu acho que ainda não... é... eu acho que eu vou saber encaixar e complementar, né, cada passo um com o outro. Mas... eu acho que talvez eu ia ter algum errinho ainda no meio, talvez. Tipo, eu ia saber, mas eu teria como fazer melhor ainda (grifo nosso).

A partir do trecho se eu for ensinar por conta, sem ajuda, eu acho que ainda não, notamos que, mesmo após ter realizado uma disciplina sobre gêneros textuais e, no estágio supervisionado, ter tido contato com questões relacionadas ao ensino de LIC e à elaboração de SD, Ana ainda se mostra insegura para planejar uma SD sozinha. Neste ponto, compreendemos que a aluna-professora valoriza o coletivo de trabalho do qual faz parte (professores de LIC em formação inicial) e, ao mesmo tempo, demonstra ainda necessitar das prescrições deste grupo, que são construídas nos momentos de formação possibilitadas pelo estágio supervisionado.

Desse modo, o discurso de Ana reafirma o importante papel do estágio para a sua formação, visto que este locus permite que a docente em formação inicial compartilhe

\footnotetext{
${ }^{7} \mathrm{O}$ termo "a gente" é normalmente utilizado pelos falantes brasileiros da língua portuguesa, principalmente na oralidade, como semanticamente equivalente ao pronome pessoal reto "nós".

${ }^{8}$ De acordo com Bronckart (2007, p. 271), "os discursos interativos caracterizam-se pela presença de pronomes de primeira, segunda e terceira pessoa, que acumulam, freqüentemente, um valor dêitico e um valor anafórico (cadeias constituídas pela recorrência particularmente dos eu, você, nós, a gente em particular)".
} 
seus anseios com colegas e professores e, assim, se constitua enquanto professora de LIC. Isso posto, concordamos com Tonelli (2016), ao passo que a autora pontua que o estágio supervisionado pode ser visualizado como espaço essencial para a formação inicial de professores. No caso do ensino de LIC, especialmente, a inserção neste contexto de práticas supervisionadas se faz ainda mais importante, visto que o estágio é um dos únicos momentos nos quais o docente terá a oportunidade de aprimorar sua formação como professor de LIC.

\section{Ensino de língua inglesa para crianças}

Diante do tópico Ensino de língua inglesa para crianças, destacamos a resposta da participante Carolina, que demonstrou satisfação máxima, atribuindo nota 10 à temática. A aluna-professora afirma, inclusive, que possui muita afinidade com crianças e com a língua inglesa, reflexo de suas experiências vivenciadas na infância, como visualizamos no Excerto 3:

\footnotetext{
Excerto 3

Carolina: É... para mim é um dez, porque eu adoro (- risos). Eu adoro trabalhar com criança, porque eu acho crianças incríveis, crianças são muito inteligentes. [...] Eu gosto muito de ajudar. Eu lembro que eu fiz uma prova, né, para a XX escolher. E eu escrevi assim que eu comecei a gostar de inglês quando eu era criança, então, eu queria que as crianças gostassem tanto quanto eu gostava quando eu tinha a idade delas. Então eu sempre gostei muito dessa ideia de ensinar crianças (- risos) (grifo nosso).
}

Como podemos observar no discurso de Carolina, a participante atesta sua preferência pelo trabalho com crianças por considerá-las 'incríveis' e 'muito inteligentes', atribuindo adjetivos que considera como inerentes a esse público. Ademais, ao passo que a graduanda utiliza o vocábulo 'trabalhar' para se referir à tarefa a ser desenvolvida, Carolina demonstra reconhecer a atividade de ensino do professor de LIC como trabalho (AMIGUES, 2004; SOUZA-E-SILVA, 2004). Ainda nesse tópico, a professora revela que começou a gostar da língua inglesa quando criança e que por essa razão ansiava despertar um gosto semelhante pela aprendizagem da língua em seus alunos. Dessa forma, por meio da fala de Carolina, notamos que ela atribui um caráter totalmente positivo à prática de ensino de LIC, não citando nenhum dos desafios ou possíveis pontos negativos relacionados a esse contexto de atuação. 
Em face ao Excerto 3, inferimos que exista um considerável anseio da participante pela possibilidade de atuar profissionalmente enquanto professora de LIC e, assim, poder despertar em outras crianças o mesmo interesse pela aprendizagem da língua. Nesse sentido, entendemos que o discurso de Carolina, mesmo que de ordem individual, exprime uma demanda coletiva e urgente no que se refere à formação inicial de professores de LIC. Como pontuam Tonelli e Cristovão (2010, p. 68), visualizamos que de um lado "existe um aumento na demanda por profissionais para atuarem junto a crianças aprendendo uma língua estrangeira [...] e por outro, há uma lacuna na formação de nossos alunos nesta área do conhecimento".

\section{Ensino de língua inglesa para crianças no ambiente remoto}

No que se refere ao ensino de LIC em ambiente remoto (tópico 6 da Roda), obtivemos respostas consideravelmente discordantes. Observemos, abaixo, os pontos de vista expostos pelas professoras:

\section{Excerto 4 \\ Ana: Ah, acho que eu daria 9, porque eu gostei bastante do ensino remoto. Eu gosto bastante, mas ainda eu acho que tem as dificuldades, né. Não tem internet ou tem internet ruim, que acaba prejudicando um pouco, né. Mas eu gosto bastante do ensino remoto, se existisse internet perfeita eu daria 10 (grifo nosso). \\ Excerto 5 \\ Carolina: Eu fiquei apavorada quando começou com essa ideia, porque a gente pensa assim: "Meu Deus, criança. A criança gosta de andar, a criança gosta de fazer alguma baguncinha... criança na frente do computador não vai funcionar". [...] E também, às vezes, $\underline{\text { eu }}$ tinha alguns problemas com a conexão ou o computador travava e eu pensava: "Nossa, vai estragar a aula inteira", sabe? Então essa coisa de ensinar pela internet, eu falei até em outro trabalho que eu tive certeza de que não é o que eu quero (- risos). Dar aula online não é o que eu quero para a minha vida (- risos) (grifo nosso).}

Por meio da colocação inicial de Ana, eu gostei bastante do ensino remoto, visualizamos que ela demonstra ter se adaptado bem à proposta de ensino de LIC ambientada neste contexto, expressando seu contentamento com as aulas e as interações virtuais. Entretanto, em seguida a aluna-professora utiliza a conjunção adversativa mas para citar que este cenário também contempla fatores negativos (não tem internet ou tem 
internet ruim, que acaba prejudicando um pouco, né) que interferem negativamente na condução do trabalho docente.

Por outro lado, a fala de Carolina contrapõe a visão predominantemente positiva de Ana acerca do ensino remoto. Logo de início, Carolina declara que se sentiu apavorada quando começou com essa ideia, argumentando que devido às características próprias da criança (a criança gosta de andar, a criança gosta fazer alguma baguncinha), esse modelo de ensino não poderia ser adequado (criança na frente do computador não vai funcionar) para seu contexto.

À luz das considerações tecidas, afirmamos que os próprios dizeres das professoras em formação inicial revelam que alguns dos aspectos dificultosos do cenário em tela dizem respeito às (más) condições de acesso à internet enfrentadas por professores e alunos. Entendemos, pois, que esse apontamento nos coloca de frente às "desigualdades sociais e educacionais de nosso país" (TONELLI; KAWACHI-FURLAN, 2021, p. 92), as quais se mostram atenuadas neste momento pandêmico desafiador.

Conforme Tonelli e Kawachi-Furlan (2021, p. 84) indicam, o professor atuante no contexto remoto está vivenciando "desafios próprios, possíveis lacunas na formação docente e diversos fatores sociais e emocionais decorrentes da conjuntura atual". Sob essa perspectiva, compreendemos que a fala das professoras participantes representa um sentimento que muitos docentes têm compartilhado, visto que o deslocamento para o ambiente remoto de aprendizagem se deu em caráter emergencial, acarretando, frequentemente, em condutas não planejadas e/ou amparadas por uma formação docente adequada.

Todavia, embora o contexto remoto se mostre desafiador para o professor em formação inicial, é necessário considerar que

\begin{abstract}
A realidade de ensino contemporânea é caracterizada por mudanças, imprevisibilidade e complexidade. Portanto, os professores precisam ter flexibilidade e sensibilidade para adaptarem-se a diferentes situações e escolherem soluções plausíveis a seus contextos de atuação (BRITO; RIBAS, 2018, p. 247).
\end{abstract}

Face ao exposto, concordamos com Tonelli e Cristovão (2010, p. 68) visto que as autoras postulam que o professor de LIC deve "considerar os contextos em que atua para poder transformar sua prática docente". Desse modo, entendemos que essa transformação envolve a habilidade do professor em se adequar à realidade vivenciada (mesmo que esta seja dificultosa) e propor práticas docentes coerentes com as necessidades percebidas, como é o caso do ensino remoto atualmente. Neste cenário, defendemos que é parte do Revista X, v. 16, n. 6, p. 1632-1657, 2021. 
papel do estágio supervisionado preparar alunos-professores para lidarem com situações adversas inerentes à prática docente.

\title{
Desenvolvimento pessoal após as atividades
}

Quanto ao tópico Desenvolvimento pessoal após as atividades realizadas no âmbito do estágio supervisionado, selecionamos, conforme o Excerto 6, a seguir, a resposta de Ana como objeto de análise.

\begin{abstract}
Excerto 6
Ana: Eu acho que me fez ter uma perspectiva que eu nunca tive antes de como ser professora de inglês (- se refere ao estágio supervisionado). Ai, já fui professora pra criança, né. Lembrei agora (- risos), mas eu fui por 3 meses, eu acho, numa escola. Só que eu não gostava, sabe? Eu não gostava de verdade. Tipo... eu acho que não... eu acho que tinha me dado uma visão muito negativa pra ser professora de inglês. Daí aqui no estágio eu tive uma perspectiva totalmente... uma perspectiva muito boa, porque eu tenho vontade de fazer uma pós, tipo, voltada pro ensino pra criança, que achei muito melhor assim. Achei muito mais... eu não sei, me deu uma visão meio diferente, assim. [...] Eu acho que aqui teve mais apoio também. Que nem na escola que eu trabalhava não tinha tanto apoio. Eu sentia que eu tinha que mais pagar pra trabalhar. Tipo, era muito trabalho pra pouca coisa, sabe? E aqui não, eu acho que aqui, tipo, você vê sua produtividade, você fica satisfeito com isso. Você sente que você tá desenvolvendo, que você tá produzindo bem (grifo nosso).
\end{abstract}

Por meio do discurso de Ana, fica perceptível que ela possuía uma visão bastante negativa do papel do professor de LIC, principalmente por não ter recebido apoio na escola onde trabalhava e por não ter passado por um percurso formativo que amparasse suas práticas em sala de aula. Nesse sentido, o enunciado da aluna-professora pode ser visto como um reflexo da carência na formação inicial e/ou continuada do professor de LIC, o qual se mostra despreparado para atuar em um contexto que exige dele conhecimentos específicos que devem ser explorados ao longo de seu percurso formativo. Entretanto, após a sua inserção no estágio supervisionado, Ana pôde se desenvolver pessoalmente e mudar sua perspectiva, passando a ter mais apoio em seu trabalho docente, conseguindo visualizar sua produtividade e pretendendo até mesmo dar continuidade aos estudos em um curso de pós-graduação.

Adiante, o trecho no qual Ana afirma que aqui teve mais apoio nos permite discutir o papel imprescindível das prescrições e das autoprescrições no campo da formação de 
professores de LIC. Diante da inexistência de prescrições externas sistematizadas em documentos normativos que ofereçam diretrizes apropriadas para orientar as práticas pedagógicas do professor de LIC, entendemos que seja necessário conduzir a formação deste profissional por meio da proposição de prescrições internas que lhe auxilie a atuar adequadamente junto a seu alunado. Desse modo, ao longo desta experiência relatada, professora supervisora e professora pesquisadora buscaram ofertar prescrições para as alunas-professoras nos momentos de planejamento e de reflexão acerca das aulas, principalmente no que diz respeito ao ensino de línguas por meio de gêneros textuais e sobre as particularidades do ensino de LIC.

Além disso, destacamos que o apoio citado por Ana também se constitui por meio e a partir das interações constantes entre o coletivo de trabalho dos professores de LIC em formação inicial. Durante as práticas supervisionadas nas quais o trabalho planificado e realizado (MACHADO, 2009) se constitui, as estagiárias se ocuparam em redefinir para elas mesmas as tarefas a serem prescritas às crianças (AMIGUES, 2004), concebendo, para tanto, autoprescrições sobre seu trabalho docente. Assim, entendemos que os planejamentos colaborativos de aulas, bem como os momentos de socialização vivenciados no estágio supervisionado se apresentam enquanto oportunidades frutíferas de "reflexão acerca das atividades desenvolvidas" (TONELLI, 2016, p. 60), viabilizando a construção pessoal e profissional do professor de LIC.

Sob essa perspectiva, a fala de Ana evidencia a importância de que os cursos de letras passem a promover a formação de professores de LIC em seus currículos, por mais que essa ocorra, ainda, a partir da adoção de iniciativas locais, como indicam Tonelli, Brossi e Furio (2018) ao discorrerem sobre possíveis alternativas para a preparação profissional de docentes de LIC. Nessa perspectiva, assumimos que a formação docente é imprescindível por entendermos que "trabalhar com crianças não é uma tarefa simples. Trata-se de uma atividade complexa que exige muita preparação do professor" (CIRINO; DENARDI, 2019, p. 215), por isso a importância e a urgência da sistematização de iniciativas que se ocupem em realizar tal formação.

\section{Desenvolvimento profissional após as atividades}

Por fim, pautando-nos no princípio de que a reflexividade sobre a atividade pode revelar indícios de desenvolvimento profissional docente (FRANCESCON; CRISTOVÃO, 2020), questionamos as participantes sobre como elas avaliavam esse tópico. Por meio do levantamento da referida questão, as alunas-professoras puderam compartilhar suas impressões e revelar se se sentiam mais preparadas para atuarem com o 
ensino de LIC após a participação nas atividades do estágio supervisionado. Observemos o Excerto 7 abaixo:

\begin{abstract}
Excerto 7
Ana: É, eu acho que 10 também. [...] Eu acho que eu desenvolvi no estágio. [...] De algum modo eu ponho em prática no meu trabalho, né. O meu trabalho também é ensinar crianças, né. Só que aqui é diferente, né. Que lá a gente não tem que criar atividade, plano de aula. Mas mesmo assim, durante as aulas eu consigo colocar em prática o que eu aprendi no estágio (grifo nosso).
\end{abstract}

Considerando o excerto acima, verificamos que Ana reconhece ter se desenvolvido profissionalmente (eu acho que me desenvolvi no estágio) ao longo da sua participação no estágio. Ao dizer que durante as aulas eu consigo colocar em prática o que eu aprendi no estágio, a aluna-professora revela que conseguiu transpor os conhecimentos construídos neste contexto formativo para o seu trabalho como professora de LIC em outras esferas. Para concretizar essa transposição de conhecimentos, Ana mobilizou e aliou seus saberes teóricos e práticos em relação ao trabalho docente. Dessa forma, o agir verbalizado pela participante ratifica que o professor de LIC deve "exercer sua profissão bem fundamentado em bases teóricas, sem desconsiderar que prática e teoria estão intimamente imbricadas" (TONELLI; CRISTOVÃO, 2010, p. 68).

Acreditamos, portanto, que esse amadurecimento profissional relatado por Ana seja fruto de sua inserção nas atividades do estágio supervisionado, o qual pode ser visto enquanto um espaço de aproximação entre o docente em formação inicial e a atividade do professor de LIC, assim como sugerem Tonelli, Brossi e Furio (2018). Sobre a configuração desse contexto, concordamos que

o estágio supervisionado, ao aliar componentes teóricos e práticos, se apresenta como um lugar privilegiado para (re)construções de sentido relacionadas às teorias e às experiências de ensino-aprendizagem dos professores em formação, abrindo espaço para estes compartilharem suas compreensões, concordâncias e discordâncias em relação ao próprio discurso e ao discurso dos colegas (BRITO; RIBAS, p. 247).

Em seguida, outro ponto de destaque na fala de Ana diz respeito ao trecho em que ela afirma que em seu trabalho não é necessário criar atividade, plano de aula, indicando, provavelmente, que as ferramentas didáticas utilizadas nesse contexto são elaboradas por outras instâncias e repassadas para o uso dos professores de LIC. Entretanto, por concebermos que o trabalhador é "um verdadeiro ator e não um mero 
executor das prescrições" (MACHADO, 2007, p. 86), visualizamos a planificação das atividades e dos planos de aula como parte do processo formativo do docente de LIC. Por conseguinte, consentimos que é nos momentos de planificação que os professores podem explicitar "o conjunto de tarefas, seus objetivos, suas condições materiais e sua forma de desenvolvimento das ações projetadas pelo próprio trabalhador para atingir seus objetivos, [...]" (MACHADO, 2009, p. 81).

Seguindo uma perspectiva semelhante, a professora Carolina também declara que enxerga seu desenvolvimento profissional após ter participado do estágio supervisionado, mesmo tendo sido a sua primeira experiência enquanto professora de LIC.

\section{Excerto 8 \\ Carolina: Eu também acho que, no caso, eu vou me dar um nove, porque assim, eu não tinha trabalhado com crianças antes, então, eu não vou me dar um dez já direto assim, de cara. Mas eu acho que, por exemplo, se ano que vem a gente voltasse pessoalmente eu ia tá muito mais confortável em dar aula depois de a gente ter dado nessa bagunça que foi, assim, a gente ter que ir direto pra aula online, sabe? Eu estaria muito mais confortável em dar aula com as crianças pessoalmente. Então eu acho assim que foi muito importante até. A gente sabe, agora, como lidar com esses problemas (grifo nosso).}

O relato de Carolina nos mostra que, embora ela considere que o contexto de ensino remoto tenha sido dificultoso e até mesmo uma bagunça, ainda assim foi possível se desenvolver profissionalmente nesse cenário. Como a professora em formação inicial aponta, sua inserção no estágio supervisionado foi muito importante, visto que esse percurso formativo possibilitou que ela aprendesse a lidar com os problemas da profissão e pudesse transpor esses saberes para suas práticas futuras, as quais ela espera que passem a ocorrer presencialmente. Assim, o progresso profissional destacado por Carolina reafirma a importância de continuarmos realizando e incentivando a execução de práticas formativas por meio do estágio supervisionado, posto que este espaço reforça "a importância das leituras, discussões e reflexões propostas a alunos-professores em formação, para que possam criticamente se posicionar frente ao seu trabalho docente" (PÉREZ, 2011, p. 248).

\section{CONSIDERAÇÕES FINAIS}

Iniciamos as considerações finais recuperando o objetivo central que suscitou o desenvolvimento deste trabalho: discutir as reflexões de docentes em formação inicial 
sobre o trabalho do professor de LIC no âmbito do estágio supervisionado, a partir de textos produzidos em situação de pós-trabalho. O interesse em investigar essa questão, especificamente, partiu do nosso anseio em compreender como as participantes enxergam as ações desenvolvidas ao longo das práticas formativas empreendidas no contexto remoto de ensino-aprendizagem.

Por meio das análises tecidas, constatamos que as alunas-professoras visualizam o estágio supervisionado enquanto um espaço significativo de formação de professores de LIC, mesmo frente ao cenário inusitado de ensino remoto causado pela pandemia da covid-19. Além disso, também notamos que as participantes valorizam o ensino de LIC pautado em gêneros textuais/sequências didáticas, visto que demonstram afinidade com a adoção dessa proposta didática. Nesse ponto, entendemos que ações formativas como essas se fazem necessárias face à urgência em suprir a lacuna existente entre a alta demanda por professores de LIC e a escassa formação inicial de profissionais preparados para lidarem com as especificidades inerentes ao ensino-aprendizagem de línguas por crianças.

Além disso, as análises também nos permitiram identificar que as participantes apreciam amplamente o papel do coletivo de trabalho constituído pelos professores de LIC em formação inicial como uma confiável fonte de prescrições. As alunas-professoras demonstraram reconhecer o estágio supervisionado como um espaço que oportuniza a construção de autoprescrições que regulam seu agir como professoras de LIC. Face ao exposto, foi possível notar que elas se desenvolveram na esfera pessoal e profissional, principalmente por conta do trabalho de formação desenvolvido ao longo do estágio supervisionado, o qual incluía momentos de estudos teóricos, de observação de aulas, de planejamento docente colaborativo e, por fim, de regência de aulas às crianças no ambiente remoto.

Nessa perspectiva, diante da discussão realizada, consideramos que a veiculação deste trabalho possa contribuir consideravelmente com o fortalecimento de pesquisas científicas preocupadas em investigar as atuais necessidades do campo de formação de professores de LIC. Ademais, diante da não obrigatoriedade da formação desses profissionais nos cursos de letras, esta pesquisa aponta rotas formativas que podem inspirar professores formadores a transporem e expandirem ações como a exposta neste texto para os seus contextos de atuação, colaborando, assim, com a formação de novos profissionais de LIC preparados teórico e praticamente a exercerem sua profissão. 


\section{REFERÊNCIAS}

AMIGUES, R. Trabalho do professor e trabalho de ensino. In: MACHADO, A. R. (org.). $\mathbf{O}$ ensino como trabalho: uma abordagem discursiva. Tradução de Anna Rachel Machado. Londrina: Eduel, 2004. p. 35-53.

AVILA, P. A.; TONELLI, J. R. A. A ausência de políticas para o ensino de língua estrangeira no Ensino Fundamental I: reflexões acerca da obrigatoriedade da oferta nos currículos das escolas municipais públicas. Revista X, Curitiba, v. 13, n. 2, p. 111-122, 2018. Disponível em: https://revistas.ufpr.br/revistax/article/view/55588. Acesso em 06 jul. 2021.

BAKHTIN, M. Os gêneros do discurso. In: BAKHTIN, M. Estética da criação verbal. Tradução de Paulo Bezerra. São Paulo: Martins Fontes, 2003. p. 261-306.

BORTONI-RICARDO, S. M. O professor pesquisador: introdução à pesquisa qualitativa. São Paulo: Parábola Editorial, 2008.

BRITO, C. C. P.; RIBAS, F. C. Estágio Supervisionado de Língua Inglesa como espaço de (trans)formação de professores. Entrepalavras, Fortaleza, v. 8, n. 3, p. 244-263, out./ dez. 2018. Disponível em: http:/www.entrepalavras.ufc.br/revista/index.php/Revista/ article/view/1241/550. Acesso em 23 jul. 2021.

BRONCKART, J. P.; MACHADO, A. R. Procedimentos de análise de textos sobre o trabalho educacional. In: MACHADO, A. R. (org.). O ensino como trabalho: uma abordagem discursiva. Londrina: Eduel, 2004. p. 131-163.

BRONCKART, J. P. Atividade de linguagem, textos e discursos. Por um interacionismo Sociodiscursivo. Tradução de Anna Rachel Machado e Péricles Cunha. 2. ed. São Paulo: EDUC, 2007.

CRISTOVÃO, V. L. L. Prefácio. In: MEDRADO, B.; PÉREZ, M. (org.). Leituras do Agir Docente: A atividade educacional à luz da perspectiva interacionista sociodiscursiva. Campinas: Pontes Editores, 2011. p. 7-12.

CIRINO, D. R. S.; DENARDI, D. A. C. Há espaço para o ensino de Inglês para crianças no currículo de cursos de Letras Português-Inglês? Semina: Ciências Sociais e Humana, Londrina, v. 40, n. 2, p. 209-224, jul./dez. 2019. Disponível em: http://www.uel.br/ revistas/uel/index.php/seminasoc/article/view/35703/26726. Acesso em: 18 abr. 2021. 
DOLZ, J.; NOVERRAZ, M.; SCHNEUWLY, B. Sequências didáticas para o oral e a escrita: apresentação de um procedimento. In: SCHNEUWLY, B.; DOLZ, J. (org.). Gêneros orais e escritos na escola. Tradução de Roxane Rojo e Glaís Sales Cordeiro. 3. ed. Campinas, SP: Mercado de Letras, 2011. p. 81-108.

FRANCESCON, P.K.; CRISTOVÃO, V.L.L. O papel da reflexividade no desenvolvimento profissional docente de professores de Língua Inglesa em formação inicial. Calidoscópio, v. 18, n. 2, p. 373-392, maio/ago. 2020. Disponível em: http://revistas.unisinos.br/index. php/calidoscopio/article/view/cld.2020.182.07. Acesso em: 12 mar. 2021.

LOUSADA, E. G.; ABREU-TARDELLI, L. S.; MAZILLO, T. O trabalho do professor: revelações possíveis pela análise do agir representado nos textos. In: GUIMARÃES, A. M. M.; MACHADO, A. R.; COUTINHO, A. (org.). O interacionismo Sociodiscursivo: questões epistemológicas e metodológicas. Campinas: Mercado das Letras, 2007. p. 237-256.

MACHADO, A. R.; LOUSADA, E. G.; BARALDI, G.; ABREU-TARDELLI, L. S.; TOGNATO, M. I. R. Relações entre linguagem e trabalho educacional: novas perspectivas e métodos no quadro do interacionismo sociodiscursivo. Calidoscópio, v. 2, n. 2, p. 89-96, jul./dez. 2004. Disponível em: http://www.revistas.unisinos.br/index.php/calidoscopio/ article/view/6457. Acesso em: 15 mar. 2021.

MACHADO, A. R. Por uma concepção ampliada do trabalho do professor. In: GUIMARÃES, A. M. M.; MACHADO, A. R.; COUTINHO, A. (org.). O interacionismo Sociodiscursivo: questões epistemológicas e metodológicas. Campinas: Mercado das Letras, 2007. p. 77-97.

MACHADO, A. R. Trabalho prescrito, planificado e realizado na formação de professores: primeiro olhar. In: MACHADO, A. R.; CRISTOVÃO, V. L. L.; ABREU-TARDELLI, L. S. (org.) Linguagem e educação: o trabalho do professor em uma nova perspectiva. Campinas: Mercado das Letras, 2009. p. 79-99.

PÉREZ, M. A prescrição no trabalho docente: a voz do professor desvelando práticas e recriando ações. In: MEDRADO, B. P.; PÉREZ, M. (org.). Leituras do Agir Docente: A atividade educacional à luz da perspectiva interacionista sociodiscursiva. Campinas, SP: Pontes Editores, 2011. p. 233-251.

SOUZA-E-SILVA, M. C. P. de. O ensino como trabalho. In: MACHADO, A. R. (org.). O ensino como trabalho: uma abordagem discursiva. Londrina: Eduel, 2004. p. 81-104. 
TONELLI, J. R. A.; CRISTOVÃO, V. L. L. O papel dos cursos de Letras na formação de professores de inglês para crianças. Calidoscópio, v. 8, n. 1, p. 65-76, jan./abr. 2010. Disponível em: http://revistas.unisinos.br/index.php/calidoscopio/article/view/159. Acesso em: 23 mar. 2021.

TONELLI, J. R. A. Contextos (in)explorados no estágio supervisionado nas licenciaturas em Letras/Inglês: O lugar da observação de aulas nos dizeres de alunos-mestres. Signum: Estudos da Linguagem, v. 19, n. 2, p. 35-65, dez. 2016. Disponível em: http://www.uel.br/ revistas/uel/index.php/signum/article/view/23218. Acesso em: 29 abr. 2021.

TONELLI, J. R. A.; BROSSI, G. C.; FURIO, M. O agir de professores de inglês para crianças em formação inicial: conhecendo dois contextos. In: SILVA, A. P. P.; SANTOS, L. I. S.; PHILIPSEN, N. I. (org.). Formação, docência e práticas pedagógicas em linguagens: diferentes contextos em diálogo. Campinas: Pontes Editora, 2018. p. 231-266.

TONELLI, J. R. A.; AVILA, P. A. A inserção de línguas estrangeiras nos anos iniciais de escolarização e a Base Nacional Comum Curricular: silenciamento inocente ou omissão proposital? Revista X, Curitiba, v. 15, n. 5, p. 243-266. 2020. Disponível em: https:// revistas.ufpr.br/revistax/article/view/73340 . Acesso em: 06 jul. 2021.

TONELLI, J. R. A.; KAWACHI-FURLAN, C. J. Perspectivas de professoras de inglês para crianças: (re)planejar, (re)pensar e (trans)formar durante a pandemia (Covid-19). Signo, Santa Cruz do Sul, v. 46, n. 85, p. 83-96, jan./abr. 2021. Disponível em: https:// online.unisc.br/seer/index.php/signo/article/view/15654. Acesso em: 30 abr. 2021.

TORRESAN, M. L.; PESSOTTO, F.; BUENO, C. H. Mindfulness e coaching: alternativas para o desenvolvimento humano. Revista de Carreiras e Pessoas (ReCaPe), v. 8, n. 1, p. 130-141, 2018. Disponível em: https://revistas.pucsp.br/index.php/ReCaPe/article/ view/33385. Acesso em: 29 abr. 2021.

Recebido em: 25 jul. 2021. Aceito em: 03 set. 2021. 